\title{
Self-reported smoking status and plasma cotinine concentrations among pregnant women in the Norwegian Mother and Child Cohort Study
}

\author{
Liv G. Kvalvik', Roy M. Nilsen², Rolv Skjærven', Stein Emil Vollset', Øivind Midttun³ ${ }^{3}$ Per Magne Ueland ${ }^{4}$, Kjell Haug'
}

INTRODUCTION: Underreporting of smoking in epidemiologic studies is common and may constitute a validity problem, leading to biased association measures. In this prospective study, we validated self-reported tobacco use against nicotine exposure assessed by plasma cotinine in the Norwegian Mother and Child Cohort Study (MoBa).

METHODS: The study was based on a subsample of 2,997 women in the MoBa study who delivered infants during the period 2002-2003. Self-reported tobacco use (test variable) and plasma cotinine concentrations (gold standard) were assessed at approximately gestational week 18.

RESULTS: Daily smoking was reported by $9 \%$ of the women, occasional smoking by $4 \%$, and nonsmoking by $86 \%$ of the women. Sensitivity and specificity for self-reported smoking status were calculated using a cotinine cut-off estimated from the study population $(30 \mathrm{nmol} / \mathrm{l})$. Plasma cotinine concentrations $\geq 30 \mathrm{nmol} / \mathrm{I}$ were found in $94 \%$ of self-reported daily smokers, $66 \%$ of occasional smokers, and $2 \%$ of nonsmokers. After the numbers of self-reported nonsmokers with cotinine concentrations above the cut-off limit were added, the daily smoking prevalence increased from 9 to $11 \%$. The sensitivity and specificity for self-reported daily smoking, using $30 \mathrm{nmol} / \mathrm{l}$ as the cut-off concentration, were 82 and 99\%, respectively.

DISCUSSION: These findings suggest that self-reported tobacco use is a valid marker for tobacco exposure in the MoBa cohort.

A lthough the prevalence of maternal smoking during pregnancy has declined during the past 20 y (1-3), smoking remains a strong environmental risk factor for adverse pregnancy outcomes and complications. In 2008, $16 \%$ of pregnant Norwegian women reported smoking daily at the beginning of pregnancy, and $8 \%$ reported smoking at the end of pregnancy (3). Therefore many pregnant women continue to be exposed to tobacco smoke. This underscores the need for further epidemiologic research and public health strategies to prevent smoking during pregnancy.

In addition, there is concern about whether women report their true smoking status in epidemiologic studies. By comparing self-reported smoking status with cotinine measurements, a study on pregnant women in the west of Scotland found a $25 \%$ underestimation of true smokers from selfreported smoking habits (4). In a Swedish study, $6 \%$ of selfreported nonsmokers were probably smokers, and $3 \%$ had cotinine concentrations suggestive of passive smoking (5). Such underreporting may constitute a serious validity problem, leading to biased association measures (6).

In addition, missing data on self-reported smoking seem to be a common problem. A recent study from Norway found that $12 \%$ of pregnant women had not reported smoking habits to the population-based Medical Birth Registry of Norway (2). In Sweden, data on smoking habits during pregnancy were missing for $9 \%$ of the women, and in Denmark $4 \%$ of babies had mothers whose smoking habits had not been registered $(7,8)$.

Cotinine is the primary metabolite of nicotine and is a sensitive marker of tobacco smoking as well as use of snuff and nicotine replacements. It is commonly used as a biomarker for environmental tobacco smoke exposure $(9,10)$. In this study, we validated self-reported tobacco use in the subjects in the Norwegian Mother and Child Cohort Study (MoBa) against maternal plasma cotinine. For this purpose, we also evaluated a plasma cotinine cut-off to separate active smokers from passive smokers and nonsmokers.

\section{RESULTS}

Population Characteristics

Of the 2,997 women who were the subjects of this study, the mean maternal age at delivery was 29.8 y (SD, 4.6; range, 15-43), $44 \%$ of the subjects were pregnant for the first time, and $96 \%$ of the subjects were married or cohabiting (Table 1). A total of $63 \%$ of the subjects had prepregnancy BMI between 18.5 and $24.9 \mathrm{~kg} / \mathrm{m}^{2}$, and $42 \%$ of the subjects had education of $\leq 12 \mathrm{y}$.

\section{Self-Reported Nicotine Exposure}

Of the 2,997 subjects, 263 (8.8\%) reported daily smoking and 126 (4.2\%) reported occasional smoking during pregnancy (Table 1). A total of 1,491 subjects (50\%) reported ever smoking 
Table 1. Maternal tobacco exposure during pregnancy according to maternal characteristics among 2,997 women in the Norwegian Mother and Child Cohort Study, 2002-2003

\begin{tabular}{|c|c|c|c|c|c|c|c|}
\hline & Total & $\begin{array}{l}\text { Nonsmoking } \\
(n=2,586)\end{array}$ & $\begin{array}{c}\text { Occasional } \\
\text { smoking }(n=126)\end{array}$ & $\begin{array}{l}\text { Daily smoking } \\
\quad(n=263)\end{array}$ & $\begin{array}{l}\text { Missing } \\
(n=22)\end{array}$ & $\begin{array}{l}\text { Passive smoking } \\
\quad(n=472)\end{array}$ & $\begin{array}{l}\text { Smokeless nicotine } \\
\text { products }(n=27)\end{array}$ \\
\hline Characteristic & $n(\%)$ & $\%$ & $\%$ & $\%$ & $\%$ & $\%$ & $\%$ \\
\hline All women & $2,997(100)$ & 86 & 4.2 & 8.8 & 0.7 & 16 & 0.9 \\
\hline \multicolumn{8}{|l|}{ Maternal age (y) } \\
\hline$<25$ & $379(13)$ & 76 & 8.7 & 14 & 0.8 & 33 & - \\
\hline $25-34$ & $2,152(72)$ & 89 & 3.4 & 7.3 & 0.7 & 14 & 1.1 \\
\hline$\geq 35$ & $456(15)$ & 84 & 4.2 & 11 & 1.1 & 12 & 0.9 \\
\hline \multicolumn{8}{|l|}{ Parity } \\
\hline 0 & $1,303(44)$ & 87 & 4.5 & 8.0 & 0.6 & 20 & 1.2 \\
\hline 1 & $1,116(37)$ & 87 & 3.8 & 8.6 & 0.7 & 12 & 0.6 \\
\hline 2 & $435(15)$ & 84 & 5.1 & 10 & 1.1 & 12 & 0.9 \\
\hline$\geq 3$ & $133(4)$ & 84 & 2.3 & 13 & 0.8 & 16 & 0.8 \\
\hline \multicolumn{8}{|l|}{ Marital status } \\
\hline Single & $80(3)$ & 61 & 13 & 24 & 2.5 & 43 & 2.5 \\
\hline Cohabitating & $1,342(45)$ & 83 & 5.1 & 12 & 0.6 & 20 & 1.3 \\
\hline Married & $1,539(51)$ & 91 & 2.9 & 5.3 & 0.8 & 11 & 0.5 \\
\hline \multicolumn{8}{|c|}{ Prepregnancy BMI $\left(\mathrm{kg} / \mathrm{m}^{2}\right)$} \\
\hline$<18.5$ & $81(3)$ & 75 & 8.6 & 16 & - & 17 & 2.5 \\
\hline $18.5-24.9$ & $1,876(63)$ & 88 & 3.9 & 7.9 & 0.6 & 14 & 0.8 \\
\hline $25-29.9$ & $609(20)$ & 87 & 4.6 & 8.0 & 0.7 & 17 & 0.8 \\
\hline$\geq 30.0$ & $315(11)$ & 85 & 3.5 & 11 & 0.6 & 21 & 0.6 \\
\hline \multicolumn{8}{|c|}{ Maternal education (y) } \\
\hline$\leq 12$ & $1,254(42)$ & 77 & 6.1 & 16 & 1.0 & 26 & 0.9 \\
\hline $13-16$ & $1,166(39)$ & 92 & 3.3 & 3.9 & 0.6 & 9.4 & 1.1 \\
\hline$\geq 17$ & $500(17)$ & 95 & 1.8 & 3.2 & 0.2 & 4.8 & 0.6 \\
\hline
\end{tabular}

Information on passive smoking, maternal age, parity, marital status, prepregnancy BMI, and maternal education was missing for 20, 10, 10, 36, 116, and 77 women, respectively.

and 698 (23\%) reported daily smoking during the 3 mo before becoming pregnant. Daily smoking during pregnancy was more common among the youngest subjects, among those with higher parity, and among those who were single. Also, subjects with low prepregnancy BMI and low education smoked more than others. Similar profiles were observed for occasional smokers. Further, passive smoking was reported by 472 subjects (16\%). In the entire sample, 216 subjects $(7.2 \%)$ reported passive smoking at work, $194(6.5 \%)$ reported passive smoking at home, and $62(2.1 \%)$ reported passive smoking both at home and work. Of the 472 subjects reporting passive smoking, 111 reported being daily smokers, 38 reported occasional smoking, 321 reported being nonsmokers, and data on smoking status were missing in 2 subjects (i.e., 3.7, 1.6, 11 , and $0.1 \%$ of the total population, respectively). Overall, 27 subjects used smokeless nicotine products during pregnancy. Of these, 15 used chewing tobacco or snuff, 9 used nicotine chewing gum, 1 used a nicotine adhesive patch, and 2 used a nicotine inhaler.

\section{Cotinine Concentrations and Self-Reported Smoking Status}

Plasma cotinine concentrations increased significantly with increasing cigarette consumption in both daily smokers and occasional smokers (Table 2). Overall, plasma cotinine was correlated (Spearman) with both number of cigarettes per day ( $r=0.51 ; 95 \%$ confidence interval (CI): $0.42,0.60)$ and number of cigarettes per wk ( $r=0.48$ : 95\% CI: $0.32,0.61)$.

Among those reporting nonsmoking but passive smoking, cotinine concentrations were low (geometric mean, $1.9 \mathrm{nmol} / \mathrm{l}$ ). Subjects using smokeless nicotine products had plasma cotinine concentrations of $\sim 100 \mathrm{nmol} / \mathrm{l}$.

\section{Cotinine Cut-Off and Self-Reported Smoking}

Plasma cotinine concentrations of $>0 \mathrm{nmol} / 1$ were found in a total of 963 (32\%) subjects. A density plot of these cotinine concentrations showed two distinct distributions (Figure 1a). Using kernel density estimation and a bootstrap method, we estimated that the lowest point between the two distributions of log plasma cotinine concentrations corresponded to a geometric mean of $29.8 \mathrm{nmol} / \mathrm{l}$ (95\% CI: 20.0, 56.0) (Figure 1a,b and Table 3). To validate reported daily smoking, we excluded from the analyses occasional smokers and users of smokeless nicotine products $(n=148)$ as well as those for whom data on smoking habits were missing $(n=22)$. The corresponding overall mean sensitivity and specificity for self-reported daily 
Table 2. Plasma cotinine concentrations according to tobacco exposures during pregnancy among 2,997 women in the Norwegian Mother and Child Cohort Study, 2002-2003

\begin{tabular}{|c|c|c|c|}
\hline \multirow[b]{2}{*}{ Tobacco exposure } & \multirow[b]{2}{*}{$\begin{array}{c}\text { Total } \\
\text { number of } \\
\text { subjects }\end{array}$} & \multicolumn{2}{|c|}{ Plasma cotinine $(\mathrm{nmol} / \mathrm{l})$} \\
\hline & & $\begin{array}{l}\text { Geometric } \\
\text { mean }^{\mathrm{a}}\end{array}$ & $\begin{array}{c}95 \% \\
\text { Confidence } \\
\text { interval }\end{array}$ \\
\hline \multicolumn{4}{|l|}{ Daily smokers, cigarettes per $d$} \\
\hline All ${ }^{b}$ & 263 & 346 & 295-406 \\
\hline $1-4$ & 69 & 135 & $92.1-199$ \\
\hline $5-9$ & 103 & 430 & $344-538$ \\
\hline $10-14$ & 64 & 520 & $413-656$ \\
\hline$\geq 15$ & 22 & 645 & $505-824$ \\
\hline \multicolumn{4}{|c|}{ Occasional smokers, cigarettes per wk } \\
\hline Allc & 126 & 49.7 & $32.7-75.8$ \\
\hline $1-4$ & 44 & 16.7 & $8.2-33.8$ \\
\hline $5-9$ & 27 & 78.4 & $40.5-152$ \\
\hline $10-14$ & 24 & 99.2 & $39.8-247$ \\
\hline$\geq 15$ & 19 & 244 & $116-511$ \\
\hline \multicolumn{4}{|l|}{ Passive smokers } \\
\hline All & 472 & 8.3 & $6.5-10.5$ \\
\hline At work & 216 & 3.1 & $2.4-4.1$ \\
\hline At home & 194 & 18.1 & $12.1-26.9$ \\
\hline Both at home and at work & 62 & 23.3 & $11.3-48.2$ \\
\hline Daily smoking only & 152 & 329 & $263-410$ \\
\hline $\begin{array}{l}\text { Both daily and passive } \\
\text { smoking }\end{array}$ & 111 & 371 & $294-468$ \\
\hline Occasional smoking only & 88 & 52.6 & $31.3-88.3$ \\
\hline $\begin{array}{l}\text { Both occasional and passive } \\
\text { smoking }\end{array}$ & 38 & 43.7 & $20.7-92.3$ \\
\hline Passive smoking only & 321 & 1.8 & $1.6-2.1$ \\
\hline Smokeless nicotine products & 27 & 96.9 & $35.8-262$ \\
\hline
\end{tabular}

smoking were estimated to be $81.9 \%$ (95\% CI: $77.3,86.4)$ and 99.4\% (95\% CI 99.1, 99.7), respectively. The uncertainty in terms of percentile values appeared larger in estimates of sensitivity than in those of specificity (Figure 1c,d and Table 3).

The plasma cotinine cut-off value $(30 \mathrm{nmol} / \mathrm{l})$ was also used to validate self-reported daily smoking according to background variables, such as maternal age, parity, marital status, prepregnancy BMI, and maternal education (Table 4). A total of 296 subjects had cotinine concentrations $\geq 30 \mathrm{nmol} / \mathrm{l}$. Of these, 242 (82\%) reported daily smoking, and $54(18 \%)$ reported nonsmoking. Among the 54 subjects who reported nonsmoking but had plasma cotinine levels $\geq 30 \mathrm{nmol} / \mathrm{l}, 45$ reported ever smoking, 30 reported daily smoking during the last 3 mo before pregnancy, and 13 reported passive smoking. Adding the number of self-reported nonsmokers with cotinine concentrations above the cut-off level to the number of self-reported daily smokers resulted in an increase in daily smoking prevalence from $8.8 \%(263 / 2,997)$ to $11 \%$ $(317 / 2,997)$.

\section{Cotinine and Other Nicotine Exposures}

Among the 121 occasional smokers (excluding subjects using smokeless nicotine products), 80 (66\%) had cotinine concentrations $\geq 30 \mathrm{nmol} / \mathrm{l}$. The sensitivity for combined self-reported occasional and daily smoking was $86 \%$ (95\% CI: 82,89$)$ and the specificity was $98 \%$ (95\% CI: 97, 98).

Among the 27 subjects who used smokeless nicotine products during pregnancy, 16 reported nonsmoking, 5 reported occasional smoking, and 6 reported daily smoking. A total of 21 (78\%) had cotinine concentrations $\geq 30 \mathrm{nmol} / \mathrm{l}$.

Data on self-reported smoking habits during pregnancy were missing for only $22(0.7 \%)$ subjects; in these subjects, the cotinine concentrations were $<1(n=13),<5(n=6), 76.1(n=1)$, $475(n=1)$, and $597(n=1) \mathrm{nmol} / \mathrm{l}$.

\section{DISCUSSION}

\section{Principal Findings}

This prospective study validated self-reported smoking status against measured plasma cotinine concentrations in 2,997 pregnant women in the MoBa study. Our calculations suggested that a plasma cotinine concentration of $30 \mathrm{nmol} / 1(5.3 \mathrm{ng} / \mathrm{ml})$ would be the optimal cut-off value to separate active smokers from passive smokers and nonsmokers. By also using this cut-off value in the calculation of sensitivity and specificity, we found that self-reported smoking status had a sensitivity of $82 \%$ and a specificity of $99 \%$.

\section{Strengths and Weaknesses}

The strengths of the study were (i) it comprised a subsample of 2,997 pregnant women in the MoBa study, allowing for precise estimates overall as well as in subgroups; (ii) we had detailed self-reported data on daily and occasional smoking and on passive smoking; (iii) data on self-reported smoking were missing for only $0.7 \%$ of the subjects; and (iv) we also had the opportunity to examine smokeless nicotine exposure, such as snuff, nicotine chewing gum, nicotine adhesive patch, and nicotine inhaler.

Our study also had some limitations. One limitation is the time difference between returning the completed baseline questionnaire and the blood sampling, with respect to some of the subjects. Approximately $85 \%$ of the subjects returned the questionnaires within $4 \mathrm{wk}$ from the time of blood sampling, whereas for the other $15 \%$ this interval was longer. Because smoking behavior may change around the time of the ultrasound screening, such differences in time intervals could have led to misclassification of smokers and nonsmokers. Furthermore, subjects for whom the time span between smoking and blood sampling was large could have tested as nonsmokers based on cotinine analysis. Such misclassification would be more common among occasional smokers with a variable time span since the last cigarette.

The subjects were informed that their blood samples and those of their children would be used for research purposes, 

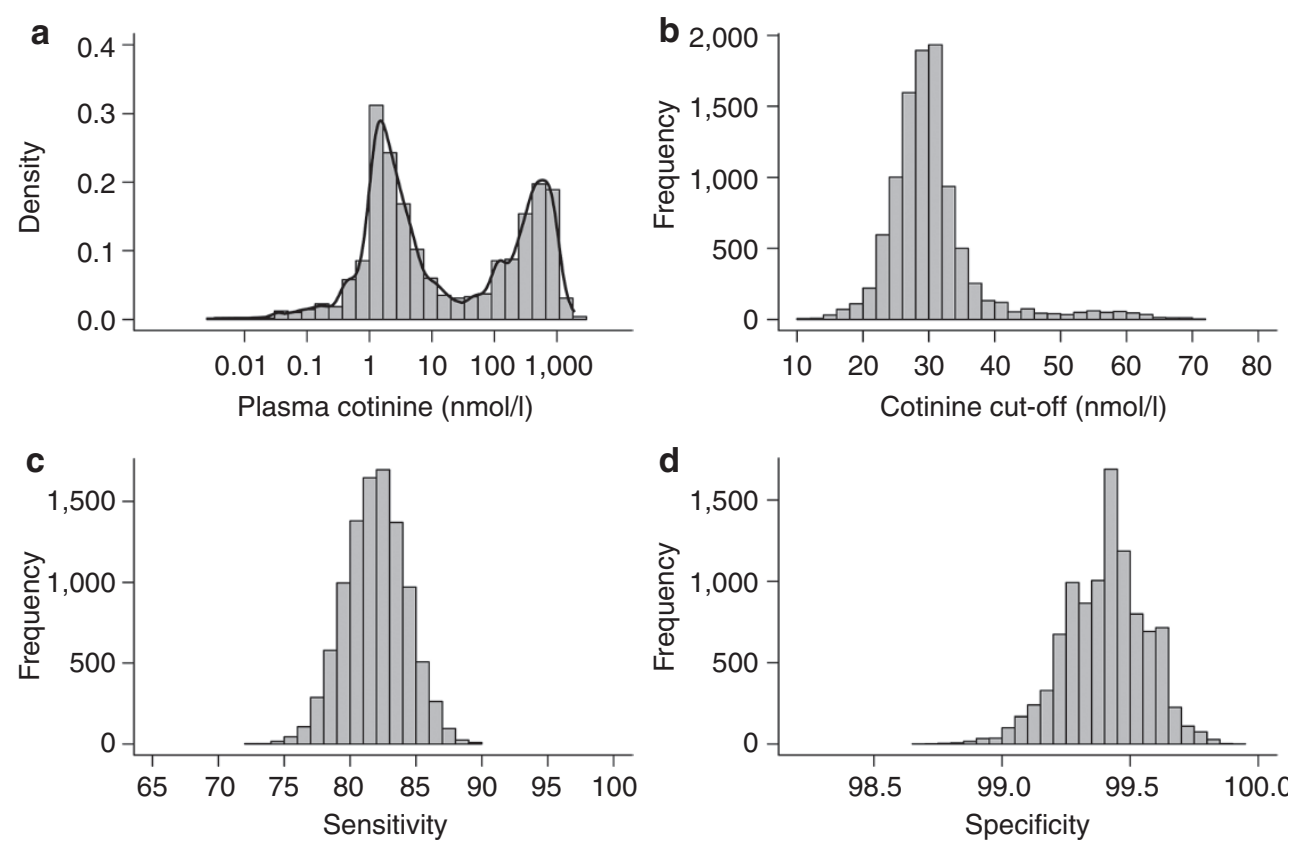

Figure 1. Distributions of log plasma cotinine, plasma cotinine cut-offs, and sensitivity and specificity for self-reported daily smokers, based on 10,000 resamples from the Norwegian Mother and Child Cohort Study, 2002-2003. (a) A density plot of log plasma cotinine concentrations obtained using kernel density estimation. (b) The distribution of the cut-offs from the 10,000 resamplings. (c,d) The distributions of the sensitivities and specificities estimated for each cut-off from the 10,000 resamplings.

Table 3. Summary statistics of cut-off between active smokers and nonsmokers/passive smokers among 2,997 women in the Norwegian Mother and Child Cohort Study, 2002-2003

\begin{tabular}{lcccccc}
\hline & & \multicolumn{5}{c}{ Percentile } \\
\cline { 3 - 7 } & Mean & 2.5 th & 25th & 50th & 75th & 97.5 th \\
\hline $\begin{array}{l}\text { Cut-off (cotinine } \\
\text { units: } \text { nmol//) }\end{array}$ & 29.8 & 20.0 & 26.5 & 29.6 & 32.2 & 56.0 \\
Sensitivity (\%) & 81.9 & 77.3 & 80.4 & 82.0 & 83.5 & 86.4 \\
Specificity (\%) & 99.4 & 99.1 & 99.3 & 99.4 & 99.6 & 99.7 \\
\hline
\end{tabular}

Estimates found by 10,000 resamplings of the observed data (nonparametric bootstrap method).

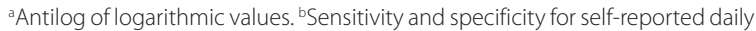
smoking: information on smoking habits during pregnancy was missing for 22 women and was excluded for 27 women using other kinds of nicotine products.

but they were not told that the blood samples would be tested for nicotine exposure. The attending nurses were also unaware of the purpose of the blood samples. It is therefore unlikely that knowledge of specific blood test(s) could have caused changes in smoking behavior before blood sampling or affected selfreported smoking status.

\section{Cotinine Cut-Off Levels in Pregnant Women}

In our study population, we observed a bimodal distribution of log plasma cotinine concentrations (Figure 1a), suggesting a separation of active smokers from passive smokers and nonsmokers $(11,12)$. By identifying the lowest point between the two distributions, we suggest a cut-off value of $30 \mathrm{nmol} / \mathrm{l}$ $(5.3 \mathrm{ng} / \mathrm{ml})(95 \% \mathrm{CI}: 20,56)$ for plasma cotinine.

Earlier studies in nonpregnant subjects have indicated serum cotinine levels of $80-85 \mathrm{nmol} / \mathrm{l}$ as a cut-off for identifying active smokers (12-14). Studies on pregnant women have used a cutoff between 57 and $99 \mathrm{nmol} / \mathrm{l}(10-18 \mathrm{ng} / \mathrm{ml})(4-5,15-19)$. On the other hand, a study based on a representative sample of the US population recommends $17 \mathrm{nmol} / \mathrm{l}(3 \mathrm{ng} / \mathrm{ml})$ as the overall cut-off (20). All these results are outside our estimated confidence limits. Therefore a general cotinine cut-off in pregnant smokers has yet to be established.

\section{Selection Bias}

A recent study compared women participating in the MoBa study to all women giving birth in Norway, using data from the Medical Birth Registry of Norway for the period 20002006 (21). The cigarette consumption at the end of pregnancy was significantly lower in the MoBa subjects than in the total population (6.9 vs. 7.4 cigarettes). There were also fewer subjects for whom the smoking habits were not known in the MoBa study than in the total population. Because the MoBa study group is a selected sample, smokers in the study may also have lower nicotine intakes than the general population. This may have resulted in a lower plasma cotinine cut-off in our study than those mentioned in other pregnancy-related studies.

\section{Validation and Underreporting of Smoking Status}

Precise and valid monitoring of smoking status in pregnancy has significant public health implications and is essential in epidemiologic research. A recent study showed higher nondisclosure rates of tobacco smoking among pregnant women than among nonpregnant women (22). The stigma associated with smoking during pregnancy might affect the veracity of self-reporting and thereby reduce the overall 
Table 4. Sensitivity and specificity for self-reported daily smoking according to the geometric mean plasma cotinine cut-off at $30 \mathrm{nmol} / \mathrm{l}$ among 2,997 women in the Norwegian Mother and Child Cohort Study, 2002-2003

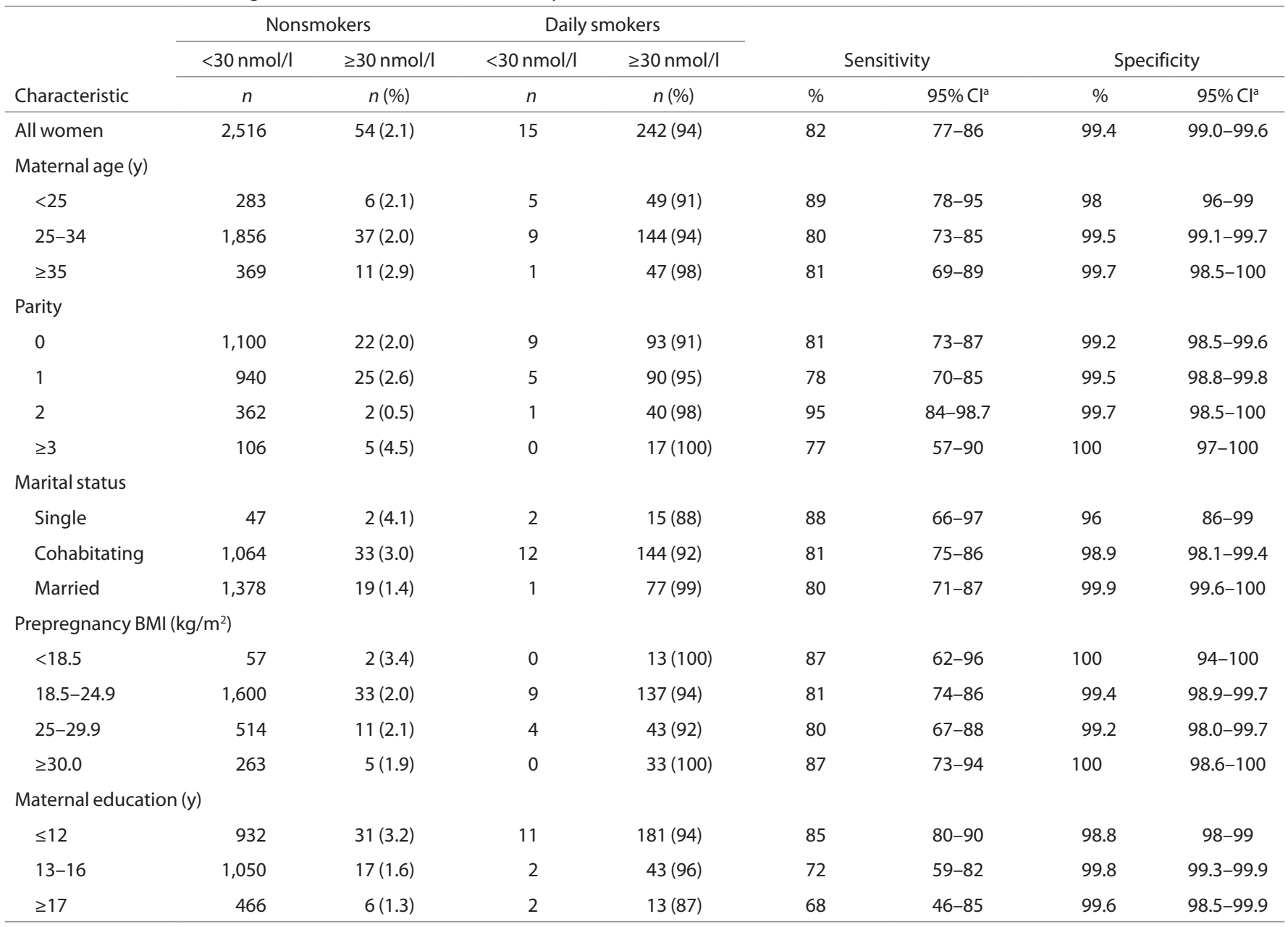

Information on smoking habits during pregnancy was missing for 22 women and was excluded for 27 women using other kinds of nicotine products.

$\mathrm{Cl}$, confidence interval.

${ }^{a} \mathrm{Cls}$ of sensitivity and specificity were calculated by the Wilson procedure without a correction for continuity.

reliability of self-reported smoking in health studies. In our study, the lowest sensitivity for self-reported smoking habits was found in subjects with the highest level of education.

There is uncertainty about the added value of measuring cotinine levels to assess smoking status (15). We found that $\sim 94 \%$ of daily smokers who did not use smokeless nicotine products had cotinine concentrations $\geq 30 \mathrm{nmol} / \mathrm{l}$. Also, $98 \%$ of nonsmokers who did not use smokeless nicotine products had cotinine concentrations below the cut-off value. A study measuring cotinine in cord serum found cotinine concentrations above the cut-off level $(80 \mathrm{nmol} / \mathrm{l}(14 \mathrm{ng} / \mathrm{ml}))$ in $88 \%$ of the subjects who were self-reported daily smokers, and cotinine concentrations below the cut-off level in $96 \%$ of the selfreported nonsmokers (19). However, other studies have found that $23-26 \%$ of women who were smokers according to their cotinine concentrations values did not report themselves as smokers $(4,6,22)$.

A study showed an overestimation of the odds ratio for the occurrence of small-for-gestational-age deliveries as well as for smoking-related reduction in birth weights, when comparing results before and after reclassification of smokers based on cotinine measurement at approximately gestational week 28 . However, it did not alter the directions of the associations between the parameters and the outcomes (6). Other studies in pregnant women that compared self-reported smoking status with cotinine values have found self-report to be a poor indicator of smoking status, with sensitivity of 47.4 and $89.5 \%$, respectively, and specificity of 94.9 and $65.3 \%$, respectively $(23,24)$.

\section{Occasional Smokers}

A Norwegian study that estimated umbilical cord serum cotinine at delivery as a measure of fetal exposure to tobacco products indicated a considerable interindividual variation in fetal nicotine exposure among newborns of occasional smoking mothers, with $46 \%$ having cotinine values above the chosen cut-off (19). In our study, $66 \%$ of the occasional smokers had cotinine concentrations above the cut-off. This might be explained by variations in the time elapsed since the last cigarette in occasional smokers. 


\section{Conclusions}

In conclusion, in a substudy of a large cohort study, we showed that self-reported smoking status in pregnancy has a sensitivity of $82 \%$ and a specificity of $99 \%$ at a plasma cotinine cut-off level of $30 \mathrm{nmol} / \mathrm{l}$. Our results indicate that self-reported smoking is a valid marker for tobacco exposure in the MoBa cohort.

\section{METHODS}

\section{Setting}

$\mathrm{MoBa}$ is a prospective population-based pregnancy study established by the Norwegian Institute of Public Health $(21,25,26)$. Participants were recruited during the period $1999-2008$, and $38.5 \%$ of the women who were invited consented to participate (27). The cohort includes 108,639 children, 90,725 mothers, and 71,574 fathers. Blood samples were obtained from both parents during pregnancy and from mothers and children (umbilical cord) at birth. Follow-up is conducted through questionnaires at regular intervals and by linkage to national health registries including the Medical Birth Registry of Norway. This study is based on version 3 of the quality-assured data files released for research in April 2007.

\section{Study Population}

For the purpose of this study, we used a subsample of 3,000 mothers with babies born during the period July 2002-December 2003. These women were selected randomly from among those who had donated blood samples at the ultrasound screening and who where registered in the Medical Birth Registry of Norway. In addition, they had returned a completed baseline questionnaire and a food frequency questionnaire during the second trimester (28). We excluded three women for whom there were no plasma cotinine data; data from 2,997 women were available for analysis.

Informed consent was obtained from each subject, and the study was approved by the regional committee for medical research ethics.

\section{Blood Sampling and Cotinine Analysis}

The blood samples (nonfasting) were collected from the subjects at weeks 17-18 into EDTA tubes, which were centrifuged within $30 \mathrm{~min}$ after collection, and placed in the refrigerators in the hospitals $\left(4^{\circ} \mathrm{C}\right)$. Samples were shipped by mail overnight to the biobank of MoBa. On the day of receipt, usually 1-2 d after the blood sample was drawn, EDTA plasma was aliquoted onto polypropylene microtiter plates (300 $\mu$ l per well, 96 -well formats), sealed with heat-sealing foil sheets, and stored at $-80^{\circ} \mathrm{C}$.

Plasma cotinine concentrations were analyzed at Bevital AS (http:// www.bevital.no) using a liquid chromatography tandem mass spectrometry method published earlier (29). The limit of detection of the method was $1 \mathrm{nmol} / \mathrm{l}(0.18 \mathrm{ng} / \mathrm{ml})$. For subjects with plasma cotinine values below limit of detection $(n=111)$, the values were imputed by assigning a random plasma cotinine value between 0 and $1 \mathrm{nmol} / \mathrm{l}$ to each of the subjects. The coefficients of variation were $2.3-2.9 \%$ (within-day) and 5.5-6.2\% (between-day). Cotinine has a half-life of $\sim 9 \mathrm{~h}$ in pregnant women (30). A serum cotinine cut-off value of $17 \mathrm{nmol} / \mathrm{l}$ $(3 \mathrm{ng} / \mathrm{ml})$ was previously recommended to distinguish smokers from nonsmokers (20).

\section{Nicotine Exposure}

The information on nicotine exposure was extracted from the baseline questionnaire (http://www.fhi.no/moba). It included information about exposure to passive smoking at work or at home and about whether the subjects had ever smoked, whether they smoked before pregnancy and during the second trimester, and whether they used smokeless nicotine products. Of note, most of the subjects returned the completed baseline questionnaire at about the time of blood sampling. Subjects who did not return the questionnaire were sent a reminder 3-4 wk after the ultrasound examination. Consequently, self-reported smoking status was available at a mean gestational age of $19.0 \mathrm{wk}(\mathrm{SD}, 4.0)$, whereas the mean gestational age at blood collection for plasma cotinine measurement was $18.2 \mathrm{wk}$ (SD, 2.1). Accordingly, in $15 \%$ of the subjects, there was a difference in gestational age of $>4 \mathrm{wk}$ between blood sampling and self-reporting of smoking status.

\section{Covariates}

Data on maternal age at delivery $(<25,25-34, \geq 35 \mathrm{y})$, marital status (married, cohabiting, single, other/missing), and parity $(0,1,2, \geq 3$ previous deliveries) were obtained from the Medical Birth Registry of Norway, whereas data on smoking habits, prepregnancy BMI $(<18.5$, $18.5-24.9,25.0-29.9$, and $\geq 30 \mathrm{~kg} / \mathrm{m}^{2}$ ), and maternal education were obtained from the MoBa baseline questionnaire. Education was measured as highest level of completed education and categorized as $\leq 12$, $13-16$ or $\geq 17 \mathrm{y}$.

\section{Statistical Analyses}

Statistical analyses were carried out using SPSS (Statistical Package for the Social Sciences) version 15 and SAS (Statistical Analysis System) version 9.2 (SAS Institute, Cary, NC). R version 2.8.1. (The R Foundation for Statistical Computing, http://www.r-project.org) software was used for graphical illustrations.

Plasma cotinine concentrations were log-transformed to achieve less skewed distribution of data and were reported as geometric means, i.e., antilog of means of the logarithmic values (31). Spearman's correlation coefficient with $95 \%$ CI was used to estimate the association between plasma cotinine and numbers of cigarettes smoked.

Active smokers were separated from passive smokers and nonsmokers by estimating the lowest point between two distinct distributions of log plasma cotinine. This was performed using a nonparametric bootstrap method (the SURVEYSELECT procedure in SAS). Briefly, we resampled randomly 10,000 times from the total population, creating 10,000 alternative data sets. For each set, we located the lowest log plasma cotinine point between two peaks using kernel density estimation. Finally, from the 10,000 point estimates, we estimated the geometric mean, which was used as the plasma cotinine cut-off between active smokers and passive/nonsmokers. The corresponding 95\% CI was constructed by extracting the 2.5 th percentile and 97.5 th percentile of the 10,000 estimates. Based on this bootstrap procedure, we simultaneously estimated the overall sensitivity and specificity for self-reported daily smoking. The uncertainty was addressed by extracting the $2.5 \mathrm{th}, 25 \mathrm{th}, 50 \mathrm{th}, 75 \mathrm{th}$, and 97.5 th percentiles.

Using the cotinine cut-off as determined by the bootstrap method, we also estimated sensitivity and specificity of self-reported daily smoking according to background variables. The estimated plasma cotinine cut-off was considered to be the "gold standard," and selfreported information was considered the "test" in sensitivity and specificity calculations. Sensitivity is the percentage of subjects with plasma cotinine concentrations above the cut-off that are correctly identified as daily smokers by self-report. Specificity is the percentage of subjects with plasma cotinine concentrations below the cut-off that are correctly identified as nonsmokers by self-report. The $95 \%$ CIs of sensitivity and specificity for self-reported daily smoking according to background variables were calculated using the Wilson procedure without a correction for continuity (32).

\section{ACKNOWLEDGMENTS}

Those conducting the Norwegian Mother and Child Cohort study are grateful to all the participating families in Norway who are taking part in this ongoing cohort study.

\section{STATEMENT OF FINANCIAL SUPPORT}

The Norwegian Mother and Child Cohort Study is supported by the Norwegian Ministry of Health and the Ministry of Education and Research, National Institutes of Health/National Institute of Environmental Health Sciences (contract no. NO-ES-75558), National Institutes of Health/ National Institute of Neurological Disorders and Stroke (grant nos. 1 UO1 NS 047537-01 and 2 UO1 NS 047537-06A1), and the Norwegian Research Council/Functional Genomics (grant no. 151918/S10). This work was supported by the Foundation to Promote Research Into Functional Vitamin B12 Deficiency.

Disclosure: The authors declare no conflict of interest. 


\section{REFERENCES}

1. Eriksson KM, Salvesen KA, Haug K, Eik-Nes SH. Smoking habits among pregnant women in a Norwegian county 1987-1994. Acta Obstet Gynecol Scand 1996;75:355-9.

2. Kvalvik LG, Skjaerven R, Haug K. Smoking during pregnancy from 1999 to 2004: a study from the Medical Birth Registry of Norway. Acta Obstet Gynecol Scand 2008;87:280-5.

3. The Medical Birth Registry of Norway, Norwegian Institute of Public Health. [Births in Norway: Annual statistics, the Medical Birth Registry2008.] (http://www.fhi.no/dokumenter/b05ede8c59.pdf.March 2010.)

4. Shipton D, Tappin DM, Vadiveloo T, Crossley JA, Aitken DA, Chalmers J. Reliability of self reported smoking status by pregnant women for estimating smoking prevalence: a retrospective, cross sectional study. BMJ 2009;339:b4347.

5. Lindqvist R, Lendahls L, Tollbom O, Aberg H, Håkansson A. Smoking during pregnancy: comparison of self-reports and cotinine levels in 496 women. Acta Obstet Gynecol Scand 2002;81:240-4.

6. England LJ, Grauman A, Qian C, et al. Misclassification of maternal smoking status and its effects on an epidemiologic study of pregnancy outcomes. Nicotine Tob Res 2007;9:1005-13.

7. The National Board of Health and Welfare, Sweden. [Smoking habits among pregnant women and parents of infants 2006.] (http://www.socialstyrelsen. se/Lists/Artikelkatalog/Attachments/8717/2008-125-18_200812518_rev. pdf)

8. National Board of Health, Denmark. [The Birth Registry 2002 (Preliminary numbers).] (http://www.sst.dk/publ/tidsskrifter/nyetal/pdf/2003/19_03. pdf 2003.)

9. Benowitz NL. Cotinine as a biomarker of environmental tobacco smoke exposure. Epidemiol Rev 1996;18:188-204.

10. Benowitz NL. Biomarkers of environmental tobacco smoke exposure. Environ Health Perspect 1999;107:Suppl 2:349-55.

11. Pirkle JL, Flegal KM, Bernert JT, Brody DJ, Etzel RA, Maurer KR. Exposure of the US population to environmental tobacco smoke: the Third National Health and Nutrition Examination Survey, 1988 to 1991. JAMA 1996;275:1233-40.

12. Nondahl DM, Cruickshanks KJ, Schubert CR. A questionnaire for assessing environmental tobacco smoke exposure. Environ Res 2005;97: 76-82.

13. Caraballo RS, Giovino GA, Pechacek TF, Mowery PD. Factors associated with discrepancies between self-reports on cigarette smoking and measured serum cotinine levels among persons aged 17 years or older: Third National Health and Nutrition Examination Survey, 1988-1994. Am J Epidemiol 2001;153:807-14.

14. Olivieri M, Poli A, Zuccaro P, et al. Tobacco smoke exposure and serum cotinine in a random sample of adults living in Verona, Italy. Arch Environ Health 2002;57:355-9.

15. McDonald SD, Perkins SL, Walker MC. Correlation between self-reported smoking status and serum cotinine during pregnancy. Addict Behav 2005;30:853-7.
16. Klebanoff MA, Levine RJ, Morris CD, et al. Accuracy of self-reported cigarette smoking among pregnant women in the 1990s. Paediatr Perinat Epidemiol 2001;15:140-3.

17. Shaw GM, Carmichael SL, Vollset SE, et al. Mid-pregnancy cotinine and risks of orofacial clefts and neural tube defects. J Pediatr 2009;154:17-9.

18. Eskenazi B, Prehn AW, Christianson RE. Passive and active maternal smoking as measured by serum cotinine: the effect on birthweight. Am J Public Health 1995;85:395-8.

19. Nafstad P, Kongerud J, Botten G, et al. Fetal exposure to tobacco smoke products: a comparison between self-reported maternal smoking and concentrations of cotinine and thiocyanate in cord serum. Acta Obstet Gynecol Scand 1996;75:902-7.

20. Benowitz NL, Bernert JT, Caraballo RS, Holiday DB, Wang J. Optimal serum cotinine levels for distinguishing cigarette smokers and nonsmokers within different racial/ethnic groups in the United States between 1999 and 2004. Am J Epidemiol 2009;169:236-48.

21. Nilsen RM, Vollset SE, Gjessing HK, et al. Self-selection and bias in a large prospective pregnancy cohort in Norway. Paediatr Perinat Epidemiol 2009;23:597-608.

22. Dietz PM, Homa D, England LJ, et al. Estimates of nondisclosure of cigarette smoking among pregnant and nonpregnant women of reproductive age in the United States. Am J Epidemiol 2011;173:355-9.

23. Burstyn I, Kapur N, Shalapay C, et al. Evaluation of the accuracy of selfreported smoking in pregnancy when the biomarker level in an active smoker is uncertain. Nicotine Tob Res 2009;11:670-8.

24. Britton GR, Brinthaupt J, Stehle JM, James GD. Comparison of self-reported smoking and urinary cotinine levels in a rural pregnant population. J Obstet Gynecol Neonatal Nurs 2004;33:306-11.

25. Magnus P, Irgens LM, Haug K, Nystad W, Skjaerven R, Stoltenberg C. Cohort profile: the Norwegian Mother and Child Cohort Study (MoBa). Int J Epidemiol 2006;35:1146-50.

26. Rønningen KS, Paltiel L, Meltzer HM, et al. The biobank of the Norwegian Mother and Child Cohort Study: a resource for the next 100 years. Eur J Epidemiol 2006;21:619-25.

27. The Norwegian Institute of Public Health. Norwegian Mother and Child Cohort Study. Revised protocol. End of enrolment - Protocol II. (http:// www.fhi.no/dokumenter/346045b550.pdf)

28. Nilsen RM, Vollset SE, Monsen AL, et al. Infant birth size is not associated with maternal intake and status of folate during the second trimester in Norwegian pregnant women. J Nutr 2010;140:572-9.

29. Midttun $\varnothing$, Hustad S, Ueland PM. Quantitative profiling of biomarkers related to B-vitamin status, tryptophan metabolism and inflammation in human plasma by liquid chromatography/tandem mass spectrometry. Rapid Commun Mass Spectrom 2009;23:1371-9.

30. Dempsey D, Jacob P 3rd, Benowitz NL. Accelerated metabolism of nicotine and cotinine in pregnant smokers. J Pharmacol Exp Ther 2002;301:594-8.

31. Bland JM, Altman DG. Transformations, means, and confidence intervals. BMJ 1996;312:1079.

32. Vollset SE. Confidence intervals for a binomial proportion. Stat Med 1993;12:809-24. 